\title{
The Association Between In Vitro Propiconazole Sensitivity and Field Efficacy of Five New England Sclerotinia homoeocarpa Populations
}

James T. Popko, Jr., Chang-Ho Ok, Katie Campbell-Nelson, and Geunhwa Jung, Department of Plant, Soil and Insect Sciences, University of Massachusetts, Amherst 01003-9320

\begin{abstract}
Popko, J. T., Jr., Ok, C.-H., Campbell-Nelson, K., and Jung, G. 2012. The association between in vitro propiconazole sensitivity and field efficacy of five New England Sclerotinia homoeocarpa populations. Plant Dis. 96:552-561.

Dollar spot (Sclerotinia homoeocarpa) is a major turfgrass disease requiring fungicide application to maintain acceptable conditions for golf. A 2-year field experiment was conducted to determine the association between field efficacy of propiconazole and in vitro fungicide sensitivity of isolates from five $S$. homoeocarpa populations. Four golf courses with prior propiconazole exposure (Hartford Golf Club, Hickory Ridge Country Club, Shuttle Meadow Country Club, and Wintonbury Hills Golf Club), and a baseline site with no prior propiconazole exposure (Joseph Troll Turf Research Facility) were chosen as field sites. Experimental plots at each site received the following treatments at 21-day intervals: untreated, propiconazole $(0.44,0.88,1.32$, and $1.76 \mathrm{~kg}$ a.i. ha $\left.{ }^{-1}\right)$, and chlorothalonil $\left(8.18 \mathrm{~kg}\right.$ a.i. ha- $\left.{ }^{-1}\right) . S$. homoeocarpa isolates were sampled at three time points during 2009 and 2010: initial (directly before fungicide treatment), 7 days after treatment (DAT), and 21 days after the last treatment. Isolates sampled from dollar spot infection centers at 7 DAT (2009 and 2010) were

considered to exhibit "practical field resistance". In parallel, $S$. homoeocarpa isolates from each site were assayed for in vitro sensitivity to propiconazole by determining relative mycelium growth percentages (RMG\%) on potato dextrose agar amended with propiconazole at a discriminatory concentration of $0.1 \mu \mathrm{g}$ a.i. $\mathrm{ml}^{-1} . S$ homoeocarpa isolates from the four exposed populations displayed significantly higher RMG\% values than the baseline population. In general, field efficacy at all propiconazole rates tested was lower at the four locations with prior propiconazole exposure when compared with the baseline population. Increased RMG\% values on the propiconazole discriminatory concentration $0.1 \mu \mathrm{g}$ a.i. $\mathrm{ml}^{-1}$ were associated with decreased relative control values for all propiconazole rates in 2009 and 2010. Results suggest RMG values above 50\% at the propiconazole discriminatory concentration of $0.1 \mu \mathrm{g}$ a.i. $\mathrm{ml}^{-1}$ may be a suitable threshold for detection of $S$. homoeocarpa isolates that cause practical DMI field resistance.
\end{abstract}

Dollar spot, caused by the ascomycete fungus Sclerotinia homoeocarpa F.T. Benn., is a major turfgrass disease causing significant damage to turfgrass swards from May to October on North American golf courses $(1,9,37,39)$. Dollar spot can occur on a broad range of cool- and warm-season grasses but is of most significance on annual bluegrass (Pоа аппиа L.) and creeping bentgrass (Agrostis stolonifera L. syn. = A. palustris Huds), which constitute a large portion of finely managed turfgrass found on golf course fairways, putting greens, and tee boxes $(9,37,39)$.

Cultural practices often do not provide adequate dollar spot control, and multiple fungicide applications are made each year to maintain acceptable turf quality $(37,39)$. Frequent fungicide applications on golf courses have led to the selection of S. homoeocarpa isolates resistant to benzimidazole and dicarboximide fungicide classes, and reduced sensitivity to the sterol demethylation inhibitor (DMI) fungicide class $(8,10,16)$. Previous monitoring studies from across the United States and Canada have confirmed that resistance and reduced sensitivity to the aforementioned fungicide classes is widespread $(2,4,15,16,20-22,32,35,38)$. Putman et al. (35) recently confirmed that $S$. homoeocarpa isolates collected from golf courses in the northeastern United States were resistant to the benzimidazole and dicarboximide fungicides and exhibited reduced sensitivity to DMI fungicides. Confirmation of reduced DMI sensitivity in the Northeast is of great concern because DMI fungicides are extensively used for dollar spot control. Moreover, golf course fairways and tee boxes consist of considerable acreage (approximately 25 to 40 acres per 18 holes); therefore, practitio-

Corresponding author: G. Jung, E-mail: jung @psis.umass.edu

Accepted for publication 2 November 2011.

http://dx.doi.org/10.1094/PDIS-06-11-0524

(C) 2012 The American Phytopathological Society ners prefer systemic fungicides that provide longer application intervals than contact fungicides.

DMI fungicides interrupt biosynthesis of ergosterol, which is an essential component of fungal cell membranes. DMI fungicides target the cytochrome P-450 monooxygenase enzyme $14 \alpha$-demethylase and prevent it from catalyzing the demethylation of lanosterol $(23,24)$. Mechanisms of reduced DMI sensitivity among various fungi have been reported to require increased expression of either the CYP51 gene (which encodes 14 $\alpha$-demethylase) or efflux transporter genes $(17,18,26,28,29)$. Despite work within other fungal systems, the genetic mechanism of DMI insensitivity remains unclear in $S$. homoeocarpa (27). In vitro fungicide sensitivity assays that measure relative mycelium growth (RMG) are used to estimate DMI sensitivity.

Reduced DMI sensitivity has been reported to develop gradually in fungal populations over time and exhibit a shift toward reduced DMI sensitivity in vitro $(3,11,14,30)$. Reduced in vitro sensitivity to DMI fungicides has been demonstrated to result in reduced field efficacy; however, complete fungicide failure has rarely been observed in field and greenhouse efficacy testing studies $(13,25$, $30,31,41)$. The quantitative nature in which reduced DMI sensitivity is expressed under field conditions has made defining practical DMI field resistance an imprecise and arduous task. Golembiewski et al. (16) conducted field efficacy testing on an $S$. homoeocarpa population with reduced DMI sensitivity and observed significant reductions in field efficacy with fenarimol, propiconazole, and triadimefon during 3 years of field trials. Burpee (5) also observed reduced efficacy of propiconazole and propiconazole tank mixtures in plots inoculated with an S. homoeocarpa isolate, with reduced DMI sensitivity and longer residual efficacy in plots inoculated with a DMI-sensitive isolate. Miller et al. (32) came to a similar conclusion based on inoculated greenhouse trials with $S$. homoeocarpa isolates exhibiting a range of in vitro sensitivities to DMI fungicides. Gilstrap et al. (15) established that repeated applications of propiconazole reduced in vitro 
propiconazole sensitivity over a 3-year period; however, field efficacy data were not reported in the study. Despite multiple accounts of reduced DMI efficacy or reduced in vitro sensitivity values in previous studies, the association between the reduced DMI field efficacy and the RMG values of isolates causing practical field resistance still remains unclear in turfgrass $(5,15,16,32,35)$. Koch et al. utilized a single discriminatory concentration of propiconazole at $0.1 \mu \mathrm{g}$ a.i. $\mathrm{ml}^{-1}$ to detect DMI sensitivity differences in $S$. homoeocarpa populations on golf courses (22). Because the propiconazole discriminatory concentration of $0.1 \mu \mathrm{g}$ a.i. $\mathrm{ml}^{-1}$ has been proven to detect RMG differences in DMI sensitivity among $S$. homoeocarpa populations, this discriminatory concentration was chosen here for examining the association between in vitro sensitivity and practical propiconazole field resistance.

DMI fungicides are labeled to control dollar spot for 14 to 21 days; therefore, practical DMI field resistance can be regarded as the appearance of dollar spot infection centers less than 14 days after application of any DMI fungicide properly applied at the label rate. To determine the sensitivity of $S$. homoeocarpa isolates causing reduced field efficacy, we collected $S$. homoeocarpa isolates from dollar spot infection centers 7 days after propiconazole application. The objectives of this study were to (i) conduct propiconazole field efficacy testing on five diverse $S$. homoeocarpa populations (one baseline population and four exposed populations) for 2 years; (ii) monitor in vitro propiconazole sensitivity of the five $S$. homoeocarpa populations before, 7 days after, and approximately 21 days after propiconazole application over a 2-year period; and (iii) estimate the relationship between in vitro propiconazole sensitivity and field efficacy.

\section{Materials and Methods}

Site selection and plot design. Four golf courses and one University research facility from Connecticut and Massachusetts were chosen and represented a range of ages and 5-year DMI fungicide spray histories (Table 1). The Joseph Troll Turf Research Facility (JTRF) area examined in this study has not been exposed to DMI fungicides and represented the baseline population. The 5year DMI application histories of Hartford Golf Club (HGC), Hickory Ridge Country Club (HRCC), Shuttle Meadow Country Club (SMCC), and Wintonbury Hills Golf Club (WBGC) are listed in Table 1. All five sites consisted of a mixture of annual bluegrass and creeping bentgrass and were mowed at a typical fairway height of approximately $1.3 \mathrm{~cm}$.

Experimental plots were set up in a randomized complete block design with four replications. Individual plot size measured 0.91 by $1.83 \mathrm{~m}$, with $0.31-\mathrm{m}$ buffer strips between each plot for HRCC and JTRF. Buffer strips were not included in the plot design at HGC, SMCC, and WBGC due to plot size restrictions. The following treatments were applied at all sites: propiconazole (Banner MAXX 1.3ME; Syngenta Crop Protection, Greensboro, NC) applied at $0.44,0.88,1.32$, and $1.76 \mathrm{~kg}$ a.i. $\mathrm{ha}^{-1}$; chlorothalonil (Daconil Ultrex 82.5WDG; Syngenta Crop Protection) applied at $8.18 \mathrm{~kg}$ a.i. $\mathrm{ha}^{-1}$; and an untreated control. The propiconazole rates of 0.44 and $0.88 \mathrm{~kg}$ a.i. $\mathrm{ha}^{-1}$ are the low and high labeled rates, respectively. The multisite fungicide chlorothalonil was included because fungicide resistance has not been reported to this active ingredient. Chlorothalonil is a contact fungicide and the suggested curative application interval is 14 days; therefore, some level of disease was expected 14 days after treatment (DAT). Applications were made at 21-day intervals for all of the treatments at all five locations.

Fungicides were applied at a nozzle pressure of $275.8 \mathrm{kPa}$ using a $\mathrm{CO}_{2}$ pressurized boom sprayer equipped with two XR Teejet 8004 VS nozzles. All fungicides were agitated by hand and applied at the equivalent of $81.5 \mathrm{ml} \mathrm{m}^{-2}$. Disease severity ratings were taken approximately every 7 days by counting individual dollar spot infection centers per plot, beginning on the date of the first fungicide application until 21 days after the last fungicide application was made. Due to differences in disease pressure, field efficacy testing began at differing dates among locations, and the number of total applications for each year is listed in Table 2. The area under the disease progress curve (AUDPC) was calculated for the number of infection centers at each location for both years using the formula $\Sigma\left[\left(y_{i}+y_{i+1}\right) / 2\right]\left(t_{i+1}-t_{i}\right)$, where $i=1,2,3, \ldots, n-1$ and $y_{i}$ is the amount of disease (number of infection centers) at the time $t_{i}$ (days) of the $i$ th rating (7). AUDPC values were converted into relative control percentage (RC\%) with the following formula: [(untreated - fungicide treatment)/untreated] $\times 100=\mathrm{RC} \% . \mathrm{RC} \%$ data were analyzed to determine the effect of location and treatment for each year separately using analysis of variance in PROC GLM (SAS v. 9.1.3; SAS Institute, Cary, NC). The location-treatment interaction was of most interest and was sliced by treatment. If significant differences existed among locations within treatment, Tukey's highly significant difference (HSD) test was used for RC\% mean separation $(P<0.05)$.

Isolate collection and in vitro propiconazole sensitivity. The initial sampling was conducted when sufficient dollar spot infection centers (approximately 10 infections per plot) were observed in 2009 and 2010. Ten samples were taken from different individual infection centers in each treatment plot by selecting individual grass blades per infection center that showed symptomatic infection (bleached hourglass lesions). Sampling of $S$. homoeocarpa isolates were performed three times in 2009 and 2010 as follows: (i) prior to the first fungicide treatment, (ii) 7 DAT, and (iii) approximately 21 days after the final fungicide treatment. Samples collected 7 DAT were from dollar spot infection centers with active mycelia or recently developed lesions at all locations in 2009 and 2010, except JTRF, due to the absence of dollar spot infection centers on all propiconazole-treated plots.

Fungal isolation followed the procedures described by Jo et al. (21). In brief, symptomatic leaf blades were individually sampled from dollar spot infection centers and stored in $1.5-\mathrm{ml}$ polypropylene microcentrifuge tubes until isolation (within $24 \mathrm{~h}$ ). Acidified potato dextrose agar (APDA) was prepared by adding $1 \mathrm{ml}$ of $85 \%$ lactic acid (Fisher Scientific, Fair Lawn, NJ) per 1 liter of fullstrength potato dextrose agar (PDA) (Difco Laboratories, Detroit) after PDA was sterilized for $45 \mathrm{~min}$ at $121^{\circ} \mathrm{C}$ in an autoclave (Tuttnauer $3850 \mathrm{M}$, Hauppauge, NY). APDA was poured into 60-by-15$\mathrm{mm}$ petri plates (Krackler Scientific, Inc., Albany, NY), allowed to solidify, and stored at $2^{\circ} \mathrm{C}$. After sample collection, individual leaf blades were surface sterilized for $1 \mathrm{~min}$ in $3 \%$ sodium hypochlorite solution, rinsed for $1 \mathrm{~min}$ once in sterile deionized water, air dried on sterile filter paper, and then placed on APDA petri plates. Petri plates were then stored at $25^{\circ} \mathrm{C}$ for 2 to 3 days. Following incubation, $S$. homoeocarpa isolates were identified based on colony morphology and compared with known reference isolates. Pure cultures of $S$. homoeocarpa were obtained by subculturing 3-mm plugs of APDA media onto PDA and stored at $25^{\circ} \mathrm{C}$.

In vitro fungicide sensitivity assays were conducted after $S$. homoeocarpa isolates had grown in pure culture for 2 to 3 days. Propiconazole-amended PDA was prepared by performing a serial dilution of commercial-grade propiconazole in sterile deionized water (Banner MAXX 1.3EC; Syngenta Crop Protection), and the final concentration in PDA was $0.1 \mu \mathrm{g}$ a.i. $\mathrm{ml}^{-1}$ (21). Agar plugs (5-

Table 1. Location, age, and demethylation inhibitor (DMI) fungicide history of field sites

\begin{tabular}{llcc}
\hline $\begin{array}{l}\text { Golf } \\
\text { course }^{\mathbf{y}}\end{array}$ & \multicolumn{1}{c}{ Location } & $\begin{array}{c}\text { Year } \\
\text { established }\end{array}$ & $\begin{array}{c}\text { Average DMI } \\
\text { application/year }^{\mathbf{z}}\end{array}$ \\
\hline JTRF & South Deerfield, MA & 1995 & 0.0 \\
SMCC & Kensington, CT & 1917 & 1.5 \\
HRCC & Hadley, MA & 1969 & 1.6 \\
HGC & Hartford, CT & 1965 & 3.4 \\
WBGC & Bloomfield, CT & 2003 & 5.0 \\
\hline
\end{tabular}

y Joseph Troll Turf Research Facility (JTRF), Shuttle Meadow Country Club (SMCC), Hickory Ridge Country Club (HRCC), Hartford Golf Club (HGC), and Wintonbury Hills Golf Club (WBGC).

${ }^{\mathrm{z}}$ Number of DMI applications was averaged over a 5-year period. DMI applications include fenarimol, metconazole, myclobutanil, propiconazole, tebuconazole, triadimefon, and triticonazole. 
$\mathrm{mm}$ ) were transferred from actively growing mycelia of the pure $S$. homoeocarpa cultures to the center PDA petri plates amended with the propiconazole discriminatory concentration $\left(0.1 \mu \mathrm{g}\right.$ a.i. $\left.\mathrm{ml}^{-1}\right)$ and nonamended PDA petri plates using a sterile 5-mm cork borer and spatula. Petri plates were kept for $48 \mathrm{~h}$ at $25^{\circ} \mathrm{C}$. S. homoeocarpa isolates were replicated twice on propiconazole-amended and nonamended PDA petri plates. At $48 \mathrm{~h}$ after transfer, three radial points approximately $120^{\circ}$ apart on the circumference of actively growing $S$. homoeocarpa colonies were measured from the edge of the transferred agar plug using digital calipers (Mahr 16EX, Göttingen, Germany). The average radial growth on propiconazole-amended PDA was divided by the average nonamended mycelial radial growth and multiplied by 100 to give the relative mycelial growth percentage (RMG\%).

To determine the reproducibility of in vitro sensitivity testing, RMG\% was calculated using the propiconazole concentration 0.1 $\mu \mathrm{g}$ a.i. $\mathrm{ml}^{-1}$ for five isolates (one from each location) and repeated five times. A new stock solution was prepared for each repeat of the assay. Analysis of variance was used to determine differences in $\mathrm{RMG} \%$ for each isolate for the main effect stock solution. Mean RMG\%, coefficient of variance, and 95\% confidence interval were calculated for each isolate based on the five replicated assays.

Analysis of variance was conducted on RMG\% for the main effects location and treatment using PROC GLM (SAS v. 9.1.3; SAS Institute). Each sample time was analyzed separately. Mean RMG\% of main effects or main effect interactions were separated using Tukey's HSD test $(P=0.05)$. Histograms describing $S$. homoeocarpa population distribution were constructed for HGC and HRCC, because both locations consisted of non-normal RMG distributions according to the Kolmogorov-Smirnov test. Furthermore, $\chi^{2}$ analysis was used to test differences in the ratio of insensitive and sensitive isolates collected from the propiconazole at $0.44 \mathrm{~kg}$ a.i. $\mathrm{ha}^{-1}$, chlorothalonil, and untreated treatments from HGC and HRCC for all samples dates. S. homoeocarpa isolates in the range of 0 to $49 \%$ and 50 to $100 \%$ RMG were designated as sensitive and insensitive, respectively. The expected number of insensitive and sensitive isolates was determined on the basis of the assumption that the total observed number of both isolates collected would be evenly distributed among treatments.

Linear regression analysis was used to determine whether a relationship between mean RMG\% of S. homoeocarpa isolates collected during the final sample date in all five locations and mean $\mathrm{RC} \%$ at the respective locations existed in 2009 and 2010 using
PROC REG. RC\% values from each replication were regressed against mean RMG\% values for each replication. Regression analysis was performed on chlorothalonil $\left(8.18 \mathrm{~kg}\right.$ a.i. $\left.\mathrm{ha}^{-1}\right)$ and all propiconazole treatments $\left(0.44,0.88,1.32\right.$, and $1.76 \mathrm{~kg}$ a.i. ha $\left.{ }^{-1}\right)$ separately. Coefficients of determination between the $\mathrm{RC} \%$ values and RMG\% values were calculated.

\section{Results}

Field efficacy, 2009 and 2010. The early summer months of 2009 were unusually cool and dollar spot severity was low in June and July. Conditions became more favorable in August and resulted in higher disease incidence among all locations. The 2010 summer months (June to August) were unusually hot and dry. These conditions resulted in lower dollar spot severity in 2010 than 2009 for all locations (except HRCC) and are reflected in mean AUDPC values for untreated plots (Table 2).

Analysis of variance determined that $\mathrm{RC} \%$ was significantly different for the main effects locations $(P=0.001)$, treatment $(P<$ $0.001)$, and location-treatment interaction $(P<0.001)$ in 2009 . The location-treatment interaction sliced by treatment determined significant differences in $\mathrm{RC} \%$ among location for all propiconazole treatments $\left(0.44,0.88,1.32\right.$, and $1.76 \mathrm{~kg}$ a.i. ha $\left.{ }^{-1}\right)$ but not chlorothalonil (8.18 kg a.i. ha ${ }^{-1}$ ) (Table 2). RC\% was significantly higher at JTRF within the propiconazole treatments at $0.44,0.88$, and $1.32 \mathrm{~kg}$ a.i. $\mathrm{ha}^{-1}$ for all other locations except SMCC (propiconazole treatments at 0.88 and $1.32 \mathrm{~kg}$ a.i. $\mathrm{ha}^{-1}$ ). The propiconazole treatments at 0.44 and $0.88 \mathrm{~kg}$ a.i. $\mathrm{ha}^{-1}$ represent the low and high label rate of propiconazole; therefore, significant reductions in field efficacy among the four exposed locations represent practical DMI field resistance. At the propiconazole rate of $1.76 \mathrm{~kg}$ a.i. ha ${ }^{-1}$, a significant difference in $\mathrm{RC} \%$ to the baseline site (JTRF) was only observed at HGC (Table 2).

Analysis of variance determined that RC\% was significantly different for the main effects location $(P=0.002)$, treatment $(P=$ $0.001)$, and location-treatment interaction $(P=0.004)$ in 2010 . The location-treatment interaction sliced by treatment determined significant differences in RC\% among locations for all propiconazole and chlorothalonil treatments (Table 2). RC\% observed at JTRF was significantly higher than all other locations, except for SMCC at all propiconazole rates (Table 2). RC\% at HGC and HRCC was significantly lower than JTRF within the propiconazole treatments of 1.32 and $1.76 \mathrm{~kg}$ a.i. ha ${ }^{-1}$ (Table 2). RC\% within the chlorothalonil treatment was significantly higher at JTRF $(91.0 \%)$

Table 2. Interaction between location and treatment for relative control percentage of dollar spot in 2009 and 2010

\begin{tabular}{|c|c|c|c|c|c|c|}
\hline \multirow[b]{2}{*}{ Year, location ${ }^{x}$} & \multirow[b]{2}{*}{ Untreated AUDPC } & \multicolumn{5}{|c|}{ Relative control of dollar spot $(\%)^{\mathrm{w}}$} \\
\hline & & PP-0.44 & PP-0.88 & PP-1.32 & PP-1.76 & CH-8.18 \\
\hline \multicolumn{7}{|l|}{$2009^{y}$} \\
\hline JTRF & $6,344.6 \pm 817.9$ & $95.4 \mathrm{a}$ & $97.5 \mathrm{a}$ & $97.6 \mathrm{a}$ & $98.2 \mathrm{a}$ & 71.0 \\
\hline SMCC & $6,827.8 \pm 696.2$ & $64.3 \mathrm{bc}$ & $87.4 \mathrm{ab}$ & $92.7 \mathrm{ab}$ & $95.8 \mathrm{a}$ & 70.0 \\
\hline HRCC & $1,492.8 \pm 781.2$ & $75.2 \mathrm{~b}$ & $80.1 \mathrm{~b}$ & $83.3 \mathrm{~b}$ & 88.9 a & 75.8 \\
\hline HGC & $5,779.6 \pm 806.7$ & $52.8 \mathrm{c}$ & $68.0 \mathrm{c}$ & $64.7 \mathrm{c}$ & $76.3 \mathrm{~b}$ & 75.0 \\
\hline WBGC & $5,112.3 \pm 1,065.4$ & $66.6 \mathrm{~b}$ & $74.2 \mathrm{c}$ & $83.6 \mathrm{~b}$ & 89.9 a & 68.4 \\
\hline Location $\times$ treatment & $\ldots$ & $* * *$ & $* * *$ & $* * *$ & $* * *$ & NS \\
\hline \multicolumn{7}{|l|}{$2010^{z}$} \\
\hline JTRF & $2,061.5 \pm 887.3$ & $95.8 \mathrm{a}$ & $96.6 \mathrm{a}$ & $97.9 \mathrm{a}$ & $97.8 \mathrm{a}$ & $91.0 \mathrm{a}$ \\
\hline SMCC & $709.6 \pm 83.5$ & $73.5 \mathrm{ab}$ & $86.9 \mathrm{ab}$ & $88.5 \mathrm{a}$ & $90.4 \mathrm{a}$ & $71.7 \mathrm{ab}$ \\
\hline HRCC & $3,178.0 \pm 1,176.4$ & $39.5 \mathrm{bc}$ & $50.5 \mathrm{bc}$ & $55.1 \mathrm{~b}$ & $71.9 \mathrm{~b}$ & $49.8 \mathrm{~b}$ \\
\hline HGC & $3,064.3 \pm 1,830.6$ & $48.8 \mathrm{bc}$ & $61.4 \mathrm{bc}$ & $18.9 \mathrm{c}$ & $59.8 \mathrm{~b}$ & $64.0 \mathrm{~b}$ \\
\hline WBGC & $1,559.3 \pm 198.3$ & $54.8 \mathrm{bc}$ & $69.4 \mathrm{bc}$ & $74.7 \mathrm{ab}$ & $83.1 \mathrm{a}$ & $62.4 \mathrm{~b}$ \\
\hline Location $\times$ treatment & $\ldots$ & $* * *$ & $* * *$ & $* * *$ & $* * *$ & $* * *$ \\
\hline
\end{tabular}

${ }^{w}$ Relative control percentage (RC\%) data were collected by counting individual infection centers and calculating area under the disease progress curve (AUDPC) values for all rating dates among all treatments. Rating began on the first date of the first fungicide application and concluded 21 days after the final application. RC\% was calculated with the following formula: [(untreated-fungicide treated)/untreated] $\times 100=\mathrm{RC} \%$. Treatment abbreviations: propiconazole $=\mathrm{PP}$ and chlorothalonil $=\mathrm{CH}$. Numbers following abbreviations represent $\mathrm{kg}$ a.i. $\mathrm{ha}^{-1}$. Means in a column followed by the same letter are not significantly different according to Tukey's HSD test $(P \leq 0.05)$; *** and NS refer to significance at $P \leq 0.001$ and not significant, respectively.

${ }^{x}$ Locations: Joseph Troll Turf Research Facility (JTRF), Shuttle Meadow Country Club (SMCC), Hickory Ridge Country Club (HRCC), Hartford Golf Club (HGC), and Wintonbury Hills Golf Club (WBGC). The location-treatment interaction was sliced by treatment and $P$ values of the respective slices are listed.

y Total fungicide applications in 2009 were as follows: $\mathrm{HGC}=3, \mathrm{HRCC}=2, \mathrm{JTRF}=4, \mathrm{SMCC}=3$, and $\mathrm{WBGC}=4$.

${ }^{\mathrm{z}}$ Total fungicide applications in 2010 were as follows: $\mathrm{HGC}=3, \mathrm{HRCC}=3, \mathrm{JTRF}=3, \mathrm{SMCC}=3$, and $\mathrm{WBGC}=3$. 
than at HGC (64.0\%), HRCC (49.8\%), and WBGC (62.4\%) but not SMCC $(71.7 \%)$ in Table 2.

In vitro propiconazole sensitivity, 2009 and 2010. For the five isolates examined for reproducibility of the in vitro fungicide sensitivity assay, the main-effect stock solution was not significantly different for any isolate tested $(P>0.05)$. Coefficients of variance for each isolate ranged from 8.09 to $16.27 \%$ for all isolates. The $95 \%$ confidence intervals ranged from 91 to $109 \%$ for RMG values for individual isolates. Results indicate that the assay is reproducible with a high level of consistency.

Analysis of variance of in vitro propiconazole sensitivity determined that location was significantly different $(P<0.001)$, but not treatment $(P=0.309)$ or the location-treatment interaction $(P=$ 0.940), for the initial sample in 2009. The different $S$. homoeocarpa population distributions present are illustrated in Figure 1. Mean RMG\% of S. homoeocarpa isolates collected was lowest at JTRF (18.3\%) and significantly higher RMG\% means were observed at both HGC (43.8\%) and HRCC (45.7\%) at the 2009 initial sample. S. homoeocarpa isolates from HGC and HRCC displayed bimodal distributions in which two subpopulations were present. One subpopulation consisted of isolates ranging from 10 to $40 \% \mathrm{RMG}$ and the other subpopulation was ranged from 50 to 100\% RMG (Fig. 1). SMCC (63.9\%) and WBGC (64.1\%) S. homoeocarpa isolates constituted the highest mean RMG\% and displayed unimodal population distributions at the 2009 initial sample time.

S. homoeocarpa isolates were collected from HGC, HRCC, SMCC, and WBGC 7 DAT in 2009 but not from JTRF because dollar spot infection centers were not observed within the propiconazole-treated plots 7 DAT. Location $(P<0.001)$, treatment $(P=$ $0.001)$, and the interaction $(P<0.001)$ were all significantly different within the 7-DAT sample time. The location-treatment interaction sliced by location determined that significant differences in mean RMG\% among treatments occurred within HGC and HRCC (Table 3). Within HGC, mean RMG\% of S. homoeocarpa isolates among treatments were significantly different and $S$. homoeocarpa isolates sampled from all propiconazole treatments exhibited significantly higher mean RMG\% than the untreated and chlorothalo- nil treatments (propiconazole treatment at $1.32 \mathrm{~kg}$ a.i. ha ${ }^{-1}$ was statistically similar to the chlorothalonil treatment; Table 3). Within HRCC, mean RMG\% of S. homoeocarpa isolates collected from the propiconazole treatments at $0.44,0.88$, and $1.76 \mathrm{~kg}$ a.i. $\mathrm{ha}^{-1}$ were significantly higher than mean RMG\% of $S$. homoeocarpa isolates collected from the untreated in Table 3. Due to low dollar spot severity, an insufficient number of $S$. homoeocarpa isolates were collected from the chlorothalonil treatment and the propiconazole treatment at $1.32 \mathrm{~kg}$ a.i. $\mathrm{ha}^{-1}$ at HRCC.

Location $(P<0.001)$, treatment $(P<0.001)$, and location-treatment interaction $(P=0.014)$, were all significantly different for the final sample time in 2009. The location-treatment interaction sliced by location determined significant differences in mean RMG\% among treatments only for HRCC (Table 3). S. homoeocarpa isolates collected from all propiconazole treatments (except for $1.76 \mathrm{~kg}$ a.i. $\mathrm{ha}^{-1}$ ) at $0.44,0.88$, and $1.32 \mathrm{~kg}$ a.i. ha $\mathrm{h}^{-1}$ exhibited higher mean RMG\% than $S$. homoeocarpa isolates from chlorothalonil and untreated treatments in the 2009 final sample (Table 3). In contrast, mean RMG\% of S. homoeocarpa isolates collected from HGC, JTRF, SMCC, and WBGC were similar among treatments within each respective site.

In 2010, analysis of variance determined that location, treatment, and the location-treatment interaction were significantly different $(P<0.001)$ for all sample dates (initial, 7 DAT, and final) only at HRCC (Table 3). All propiconazole treatments from HRCC contained $S$. homoeocarpa isolates with significantly higher mean RMG\% than isolates collected from the chlorothalonil and untreated treatments (except propiconazole treatments at 0.44 and $1.76 \mathrm{~kg}$ a.i. ha ${ }^{-1}$ initial and $0.44 \mathrm{~kg}$ a.i. ha ${ }^{-1} 7$ DAT; Table 3). This trend was observed at HRCC for all sample times in 2010 and was the only location in which significant differences among treatments were observed when the location-treatment interaction was sliced by location.

Histograms of all sample dates were constructed to illustrate changes in the bimodal population distribution of $S$. homoeocarpa isolates collected from HGC (Fig. 2) and HRCC (Fig. 3) because both populations contained non-normal RMG distributions. The $0.44 \mathrm{~kg}$ a.i. $\mathrm{ha}^{-1}$ rate was the only propiconazole treatment in-

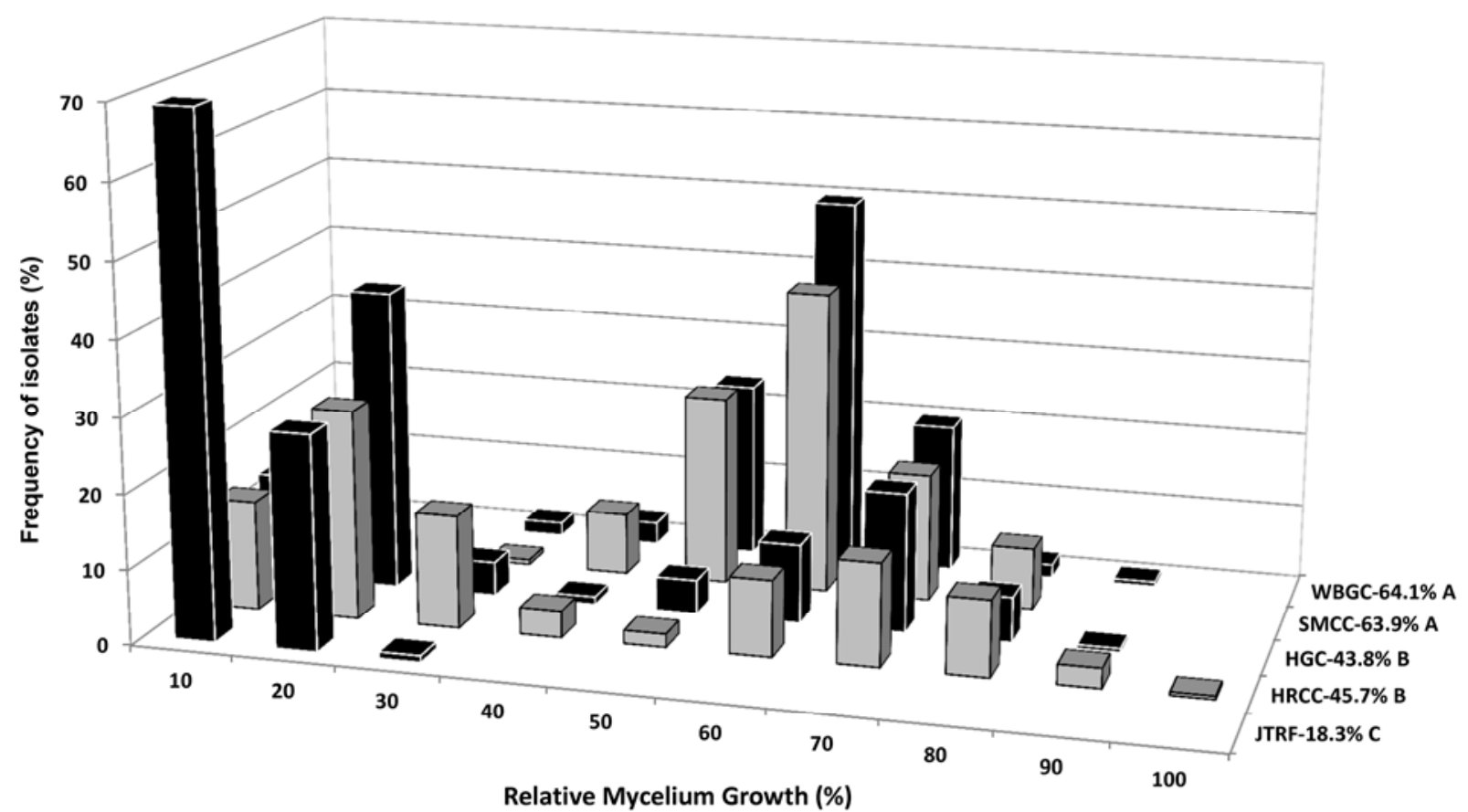

Fig. 1. Frequency distributions of relative mycelium growth percentage (RMG\%) of Sclerotinia homoeocarpa isolates from 2009 initial sampling (before fungicide application) of Hickory Ridge Country Club (HRCC) and Joseph Troll Turf Research Facility (JTRF) in Massachusetts, and Hartford Golf Club (HGC), Shuttle Meadow Country Club (SMCC), and Wintonbury Hills Golf Club (WBGC) in Connecticut evaluated on the discriminatory concentration of propiconazole at $0.1 \mu \mathrm{g} \mathrm{a.i.} \mathrm{ml}^{-1}$. Analysis of variance determined that RMG\% was different among locations $(P<0.001)$. Mean RMG is listed next to each location on the $z$-axis. RMG means followed by the same letter are not significantly different according to Tukey's honest significant difference test $(P \leq 0.05)$. 
cluded in both figures because all propiconazole rates had a similar effect on mean RMG\% (Table 3). The HGC 7-DAT S. homoeocarpa population shifted to a unimodal distribution within the propiconazole treatment at $0.44 \mathrm{~kg}$ a.i. $\mathrm{ha}^{-1}$, whereas the untreated and chlorothalonil treatments remained bimodal in distribution (Fig. 2B). A $\chi^{2}$ analysis determined that the propiconazole treatment at $0.44 \mathrm{~kg}$ a.i. $\mathrm{ha}^{-1}$ contained a significantly higher proportion of insensitive isolates at HGC during the 2009 7-DAT sample date. A $\chi^{2}$ analysis revealed that all treatments at HGC contained a similar proportion of sensitive and insensitive isolates in all sample dates following the 2009 7-DAT sample date. A shift in population distribution in the untreated and chlorothalonil treatments occurred between the 2009 7-DAT and final sample times and persisted throughout the three subsequent sample times in 2010 as well (Fig. 2B-F).

The HRCC population distribution was similar to HGC for the propiconazole treatment at $0.44 \mathrm{~kg}$ a.i. $\mathrm{ha}^{-1}$ throughout the all sample dates; however, both the untreated and chlorothalonil treat- ments remained bimodal (Fig. 3A-F). A $\chi^{2}$ analysis determined that the propiconazole treatment at $0.44 \mathrm{~kg}$ a.i. $\mathrm{ha}^{-1}$ contained a significantly higher proportion of insensitive isolates on four sample dates (2009 final sample and all 2010 sample dates) and the untreated contained a significantly higher proportion of sensitive isolates in the 2010 final sample (Fig. 3C-F). S. homoeocarpa isolates sampled from the chlorothalonil (except the 7-DAT sample time due to low sample number) and untreated treatments at HRCC remained bimodal in population distribution (Fig. 3A-F). The selection pattern observed at HRCC differed from the observed trend at HGC within the chlorothalonil and untreated plots, despite both locations beginning with nearly identical initial population distributions.

Association between in vitro propiconazole sensitivity and reduced field efficacy. Mean $\mathrm{RC} \%$ was significantly correlated with mean RMG\% on the final sample dates of all five locations for all propiconazole treatments but not chlorothalonil in 2009 (Fig. 4A-E). Mean RC\% decreased as RMG\% increased in all

Table 3. Interaction between location and treatment on mean relative mycelium growth percentage (RMG\%) of Sclerotinia homoeocarpa isolates collected from five sites in 2009 and 2010

\begin{tabular}{|c|c|c|c|c|c|c|}
\hline \multirow[b]{3}{*}{ Site, treatment ${ }^{\mathrm{z}}$} & \multicolumn{6}{|c|}{ Mean RMG\% ${ }^{y}$} \\
\hline & \multicolumn{3}{|c|}{2009} & \multicolumn{3}{|c|}{2010} \\
\hline & Initial & 7 DAT & Final & Initial & 7 DAT & Final \\
\hline \multicolumn{7}{|l|}{ JTRF } \\
\hline Untreated & 18.3 & $\ldots$ & 16.7 & 25.2 & $\ldots$ & 26.6 \\
\hline $\mathrm{CH} 8.18 \mathrm{~kg}$ & 18.8 & $\ldots$ & 14.1 & 25.6 & $\ldots$ & 25.0 \\
\hline PP $0.44 \mathrm{~kg}$ & 18.6 & $\ldots$ & 15.8 & 27.6 & $\ldots$ & 27.4 \\
\hline PP $0.88 \mathrm{~kg}$ & 18.5 & $\ldots$ & 15.7 & 24.7 & $\ldots$ & 27.4 \\
\hline PP $1.32 \mathrm{~kg}$ & 18.6 & $\ldots$ & 17.5 & 25.2 & $\ldots$ & 25.7 \\
\hline PP $1.76 \mathrm{~kg}$ & 17.1 & $\ldots$ & 17.0 & 24.7 & $\ldots$ & 29.1 \\
\hline$P$ value & 0.999 & $\ldots$ & 0.927 & 0.893 & $\ldots$ & 0.827 \\
\hline \multicolumn{7}{|l|}{ SMCC } \\
\hline Untreated & 63.2 & 55.5 & 64.5 & 57.3 & 58.0 & 62.0 \\
\hline $\mathrm{CH} 8.18 \mathrm{~kg}$ & 65.4 & $\ldots$ & 67.2 & 57.0 & 59.1 & 62.9 \\
\hline PP $0.44 \mathrm{~kg}$ & 63.4 & 57.4 & 73.5 & 58.4 & 61.2 & 65.7 \\
\hline PP $0.88 \mathrm{~kg}$ & 62.0 & $\ldots$ & 71.7 & 60.6 & 60.1 & 62.9 \\
\hline PP $1.32 \mathrm{~kg}$ & 65.7 & $\ldots$ & 70.9 & 54.2 & $\ldots$ & 63.3 \\
\hline PP $1.76 \mathrm{~kg}$ & 63.9 & $\ldots$ & 70.6 & 57.3 & $\ldots$ & 62.5 \\
\hline$P$ value & 0.961 & 0.672 & 0.081 & 0.330 & 0.845 & 0.803 \\
\hline \multicolumn{7}{|l|}{ HRCC } \\
\hline Untreated & 50.8 & $62.4 \mathrm{~b}$ & $59.8 \mathrm{~b}$ & $52.2 \mathrm{~b}$ & $56.7 \mathrm{~b}$ & $57.5 \mathrm{~b}$ \\
\hline $\mathrm{CH} 8.18 \mathrm{~kg}$ & 44.0 & & $59.1 \mathrm{~b}$ & $50.1 \mathrm{~b}$ & $66.1 \mathrm{ab}$ & $66.8 \mathrm{~b}$ \\
\hline PP $0.44 \mathrm{~kg}$ & 46.2 & $85.1 \mathrm{a}$ & $75.3 \mathrm{a}$ & $64.7 \mathrm{ab}$ & $75.4 \mathrm{ab}$ & $78.8 \mathrm{a}$ \\
\hline PP $0.88 \mathrm{~kg}$ & 45.5 & $78.9 \mathrm{a}$ & $75.6 \mathrm{a}$ & $70.4 \mathrm{a}$ & $81.1 \mathrm{a}$ & $80.1 \mathrm{a}$ \\
\hline PP $1.32 \mathrm{~kg}$ & 47.0 & $\ldots$ & $76.0 \mathrm{a}$ & $74.9 \mathrm{a}$ & $84.9 \mathrm{a}$ & $83.2 \mathrm{a}$ \\
\hline PP $1.76 \mathrm{~kg}$ & 40.6 & $86.4 \mathrm{a}$ & $73.7 \mathrm{ab}$ & $64.8 \mathrm{ab}$ & $81.5 \mathrm{a}$ & $80.5 \mathrm{a}$ \\
\hline$P$ value & 0.324 & $<0.001$ & $<0.001$ & $<0.001$ & $<0.001$ & $<0.001$ \\
\hline \multicolumn{7}{|l|}{ HGC } \\
\hline Untreated & 46.2 & $47.0 \mathrm{c}$ & 71.2 & 62.5 & 60.0 & 72.4 \\
\hline $\mathrm{CH} 8.18 \mathrm{~kg}$ & 47.5 & $51.7 \mathrm{bc}$ & 76.2 & 64.3 & 62.0 & 72.7 \\
\hline $\mathrm{PP} 0.44 \mathrm{~kg}$ & 44.2 & $77.4 \mathrm{a}$ & 77.4 & 61.1 & 63.3 & 77.3 \\
\hline $\mathrm{PP} 0.88 \mathrm{~kg}$ & 37.8 & $73.4 \mathrm{a}$ & 73.5 & 65.6 & 67.3 & 74.0 \\
\hline PP $1.32 \mathrm{~kg}$ & 46.9 & $66.3 \mathrm{ab}$ & 74.1 & 65.7 & 64.9 & 73.7 \\
\hline PP $1.76 \mathrm{~kg}$ & 40.5 & $72.9 \mathrm{a}$ & 78.5 & 63.6 & 65.0 & 73.1 \\
\hline$P$ value & 0.183 & $<0.001$ & 0.265 & 0.566 & 0.463 & 0.427 \\
\hline \multicolumn{7}{|l|}{ WBGC } \\
\hline Untreated & 61.1 & 77.4 & 82.1 & 91.2 & 78.9 & 82.3 \\
\hline $\mathrm{CH} 8.18 \mathrm{~kg}$ & 63.2 & 79.2 & 83.3 & 89.1 & 77.9 & 81.3 \\
\hline PP $0.44 \mathrm{~kg}$ & 65.6 & 76.8 & 86.3 & 91.9 & 81.9 & 82.5 \\
\hline $\mathrm{PP} 0.88 \mathrm{~kg}$ & 65.0 & 81.0 & 85.2 & 87.2 & 78.9 & 84.4 \\
\hline PP $1.32 \mathrm{~kg}$ & 65.6 & 75.8 & 84.4 & 90.8 & 80.9 & 82.6 \\
\hline PP $1.76 \mathrm{~kg}$ & 61.5 & $\ldots$ & 87.5 & 90.1 & 79.9 & 85.7 \\
\hline$P$ value & 0.786 & 0.767 & 0.615 & 0.566 & 0.898 & 0.608 \\
\hline
\end{tabular}

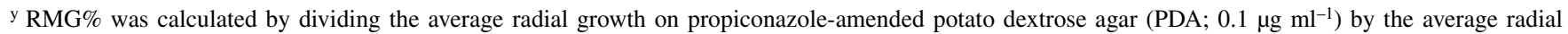
growth on nonamended PDA and multiplied by 100 to give RMG\% for each petri plate. Sample time indicates that $S$. homoeocarpa isolates were sampled prior to fungicide application at the beginning of the experiment (Initial), 7 days after treatment (7 DAT), or approximately 21 days after the final fungicide applications were made (Final). Within a sample time, means followed by the same letter are not significantly different according to Tukey's honest significant difference test $(P \leq 0.05) ; \ldots$ represents treatments in which $S$. homoeocarpa isolates were not recovered from dollar spot infection centers or dollar spot infection centers were not present at the time of sampling.

${ }^{z}$ Sites: Joseph Troll Turf Research Facility (JTRF), Shuttle Meadow Country Club (SMCC), Hickory Ridge Country Club (HRCC), Hartford Golf Club (HGC), and Wintonbury Hills Golf Club (WBGC). Treatment abbreviations: chlorothalonil $=\mathrm{CH}$ and propiconazole $=$ PP. Numbers following abbreviations represent $\mathrm{kg}$ a.i. ha ${ }^{-1}$. The location-treatment interaction was sliced by location and $P$ values of the respective slices are listed. 
propiconazole treatments. Coefficients of determination from the propiconazole treatments ranged from 0.224 to 0.601 , whereas mean $\mathrm{RC} \%$ was not associated with mean RMG\% for the chlorothalonil treatment in 2009. In contrast, mean RC\% was significantly associated with mean RMG\% on the final sample dates for all propiconazole treatments and chlorothalonil treatment, in 2010 (Fig. 4F-J). Coefficients of determination from the propiconazole treatments ranged from 0.427 to 0.660 . The coefficient of determination for chlorothalonil was 0.369 .

\section{Discussion}

The operational definition of practical fungicide resistance states: "isolates of pathogens are resistant if their frequencies have increased substantially at sites with poor fungicide performance" (25). The results in this study confirmed that (i) reduced propiconazole efficacy existed within the four golf course populations (HGC, HRCC, SMCC, and WBGC) with prior DMI fungicide exposure, (ii) the four exposed $S$. homoeocarpa populations were signifi- cantly less sensitive to propiconazole in vitro than the baseline population (JTRF), and (iii) increased RMG\% values on the propiconazole discriminatory concentration $0.1 \mu \mathrm{g}$ a.i. $\mathrm{ml}^{-1}$ were significantly correlated to decreased RC values. Therefore, the results presented herein indicate that RMG\% values of $S$. homoeocarpa isolates within the range of 50 to $100 \%$ on the propiconazole discriminatory concentration $0.1 \mu \mathrm{g}$ a.i. $\mathrm{ml}^{-1}$ correlate to practical fungicide resistance.

Previous research on $S$. homoeocarpa in turfgrass has correlated reduced in vitro DMI sensitivity with reduced DMI efficacy through inoculated field and greenhouse trials; however, the association between native $S$. homoeocarpa populations causing practical field resistance and in vitro sensitivity has remained unclear $(5,15,16,21,22,32,35)$. The determination of a threshold or level of in vitro sensitivity that results in efficacy reductions that can be classified as practical field resistance has yet to be established and is critical for making accurate recommendations for DMI fungicides. Moreover, Putman et al. (35) determined that
HGC 2009

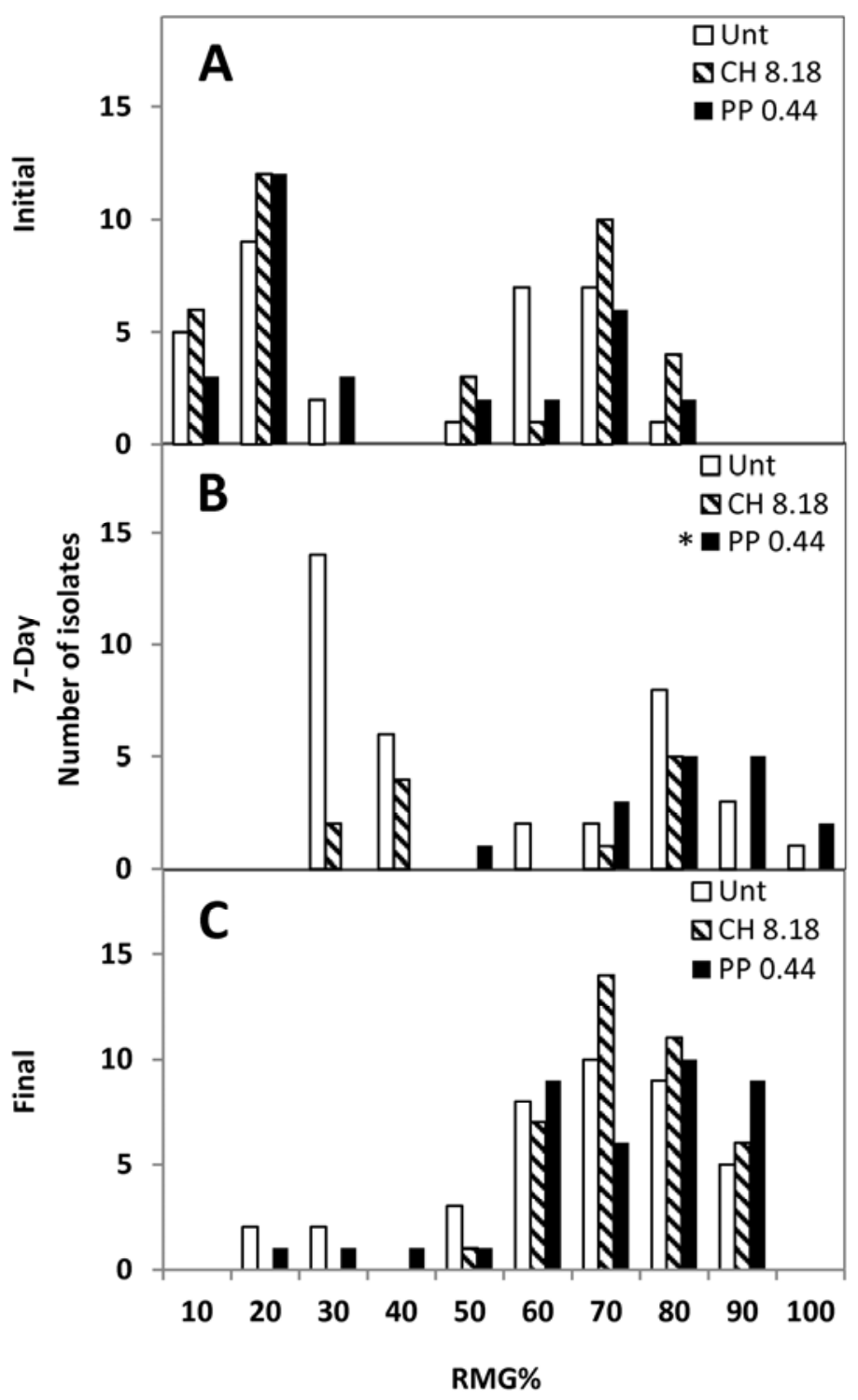

HGC 2010

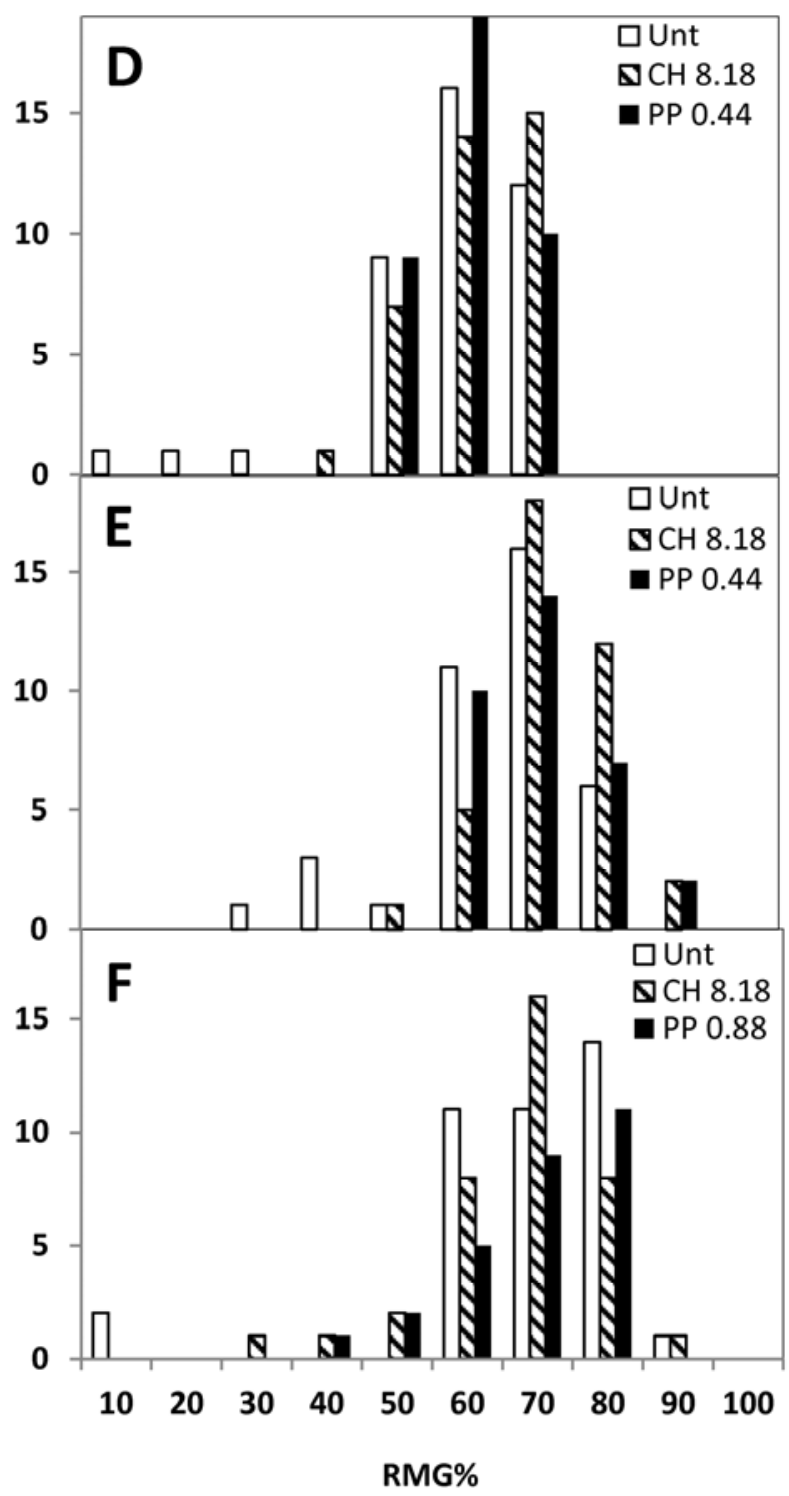

Fig. 2. Frequency distributions of relative mycelium growth percentage (RMG\%) of Sclerotinia homoeocarpa isolates on the discriminatory concentration of propiconazole at $0.1 \mu \mathrm{g}$ a.i. $\mathrm{ml}^{-1}$ from Hartford Golf Club (HGC). S. homoeocarpa isolates were collected during the A, 2009 initial; B, 20097 days after treatment (DAT); C, 2009 final; D, 2010 initial; E, 20107 DAT; and F, 2010 final sampling times. Bars represent the number of isolates collected from untreated (white), chlorothalonil at $8.18 \mathrm{~kg}^{2}$ a.i. ha ${ }^{-1}$ (hatched)m or propiconazole at $0.44 \mathrm{~kg}$ a.i. ha ${ }^{-1}$ (black) treatments. An asterisk prior to treatment in the legend represents a significant difference in the ratio of insensitive and sensitive isolates sampled from the treatment compared with the total observed number of both isolates collected from all three treatments at the given sample time according to $\chi^{2}$ analysis. 
reduced in vitro propiconazole sensitivity was present in 18 of the 20 $S$. homoeocarpa populations examined in the New England region; therefore, the ability to determine the level of insensitivity that corresponds to practical fungicide failure is of utmost importance.

In vitro fungicide sensitivity values and greenhouse efficacy testing was used in Venturia inaequalis research to determine a threshold in which practical DMI failure occurred (25). Köller et al. (25) used discriminatory concentrations of the DMIs fenarimol and myclobutanil to determine that 2 of $19 \mathrm{~V}$. inaequalis populations were significantly different from a baseline population. Fenarimol and myclobutanil in vitro sensitivity of the two insensitive $V$. inaequalis populations revealed a significant increase of isolates with relative growth $(\mathrm{RG})$ values $>80 \%$ compared with the baseline population (25). Furthermore, greenhouse efficacy testing determined that a $V$. inaequalis isolate with an RG value of $88 \%$ was partially controlled compared with one with an RG value of $42 \%$ that was completely controlled by fenarimol and myclobutanil (25). Köller et al. (25) determined that isolates with RG values >
$80 \%$ caused practical field resistance and developed the first in vitro threshold for detection of practical DMI resistance.

Our field trials conducted at HGC, HRCC, SMCC, and WBGC revealed reductions in field efficacy for the propiconazole treatments at 0.44 and $0.88 \mathrm{~kg}$ a.i. $\mathrm{ha}^{-1}$ (low and high labels rates, respectively) compared with JTRF in both years of the study (Table 2). S. homoeocarpa isolates collected from HGC, HRCC, SMCC, and WBGC were significantly more insensitive to propiconazole in vitro than those from JTRF (Fig. 1). The presence of dollar spot infection centers 7 days after propiconazole treatment at HGC, HRCC, SMCC, and WBGC enabled quantification of the in vitro propiconazole sensitivity of $S$. homoeocarpa isolates causing reduced efficacy. Mean RMG values of S. homoeocarpa isolates sampled 7 DAT from all propiconazole treatments at HGC, HRCC, SMCC, and WBGC were consistently above 50\% RMG for both years of the study and provide evidence that reduced field efficacy is caused by isolates exceeding 50\% RMG (Table 3). Moreover, the repeated observation of isolates with $>50 \%$ RMG over four geo-

HRCC 2009
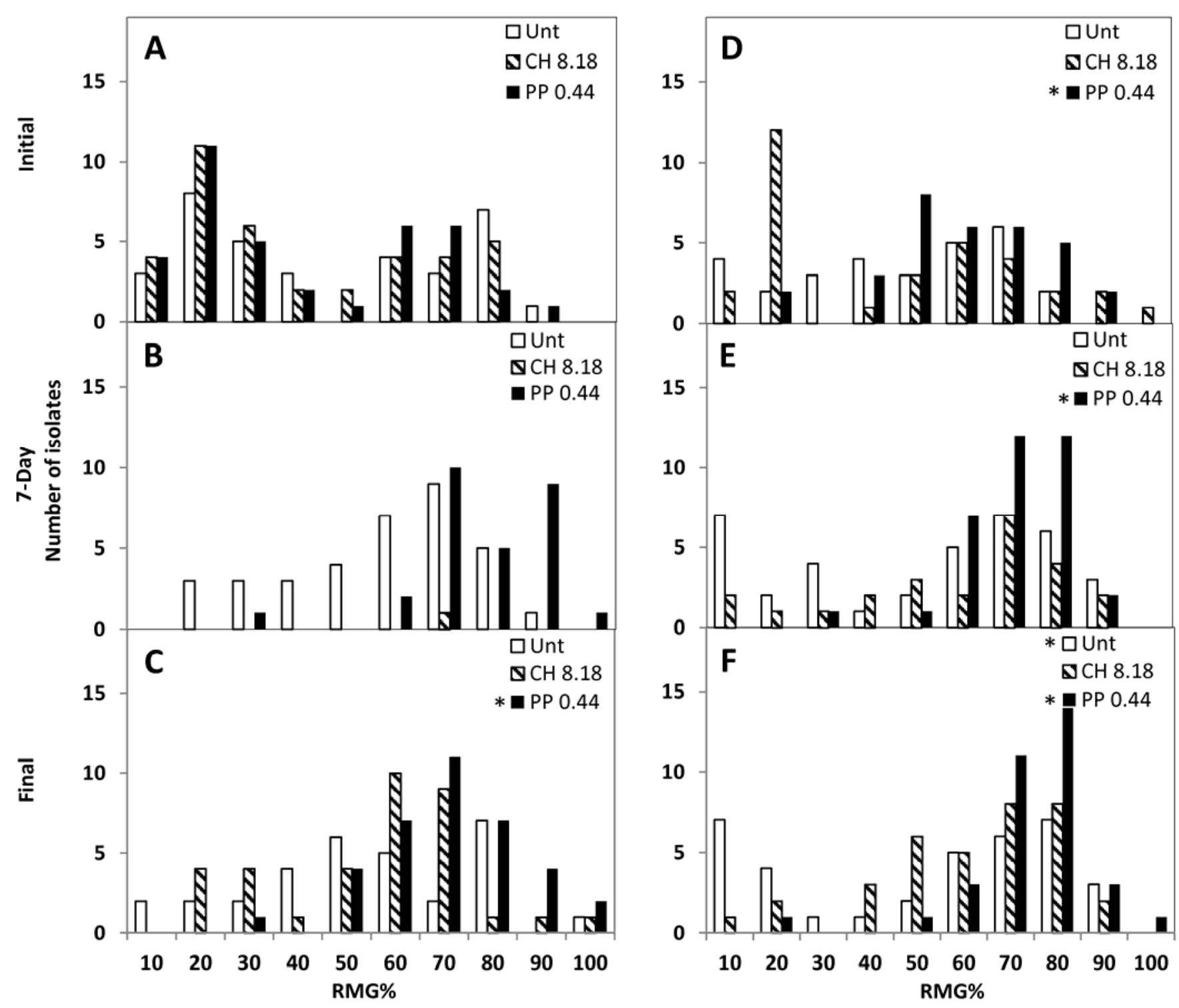

Fig. 3. Frequency distributions of relative mycelium growth percentage (RMG\%) of Sclerotinia homoeocarpa isolates on the discriminatory concentration of propiconazole at $0.1 \mu \mathrm{g}$ a.i. $\mathrm{ml}^{-1}$ from Hickory Ridge Country Club (HRCC). S. homoeocarpa isolates were collected during the A, 2009 initial; B, 20097 days after treatment (DAT); C, 2009 final; D, 2010 initial; E, 20107 DAT; and F, 2010 final sampling times. Bars represent the number of isolates collected from untreated (white), chlorothalonil at $8.18 \mathrm{~kg}^{2 . i .}$. ha ${ }^{-1}$ (hatched), or propiconazole at $0.44 \mathrm{~kg}$ a.i. ha ${ }^{-1}$ (black) treatments. An asterisk prior to treatment in the legend represents a significant difference in the ratio of insensitive and sensitive isolates sampled from the treatment compared with the total observed number of both isolates collected from all three treatments at the given sample time according to $\chi^{2}$ analysis. 
graphically separated locations adds additional merit to 50\% RMG serving as a potential threshold to determine practical field resistance to propiconazole in S. homoeocarpa. In contrast, S. homoeocarpa isolates were not collected from JTRF 7 DAT, because dollar spot infection centers were not observed within propiconazole treatments 7 DAT in both years of the study. Furthermore, mean RMG values did not exceed 50\% during any sample time in 2009 or 2010 at JTRF, which supports the theory that isolates below $50 \%$ RMG do not cause practical DMI field resistance. Therefore, these results indicate that $S$. homoeocarpa isolates with RMG values $>50 \%$ are capable of causing significant field efficacy reductions or practical DMI field resistance.

The discovery of different population distributions (bimodal and unimodal) was a novel finding that has not been previously re-
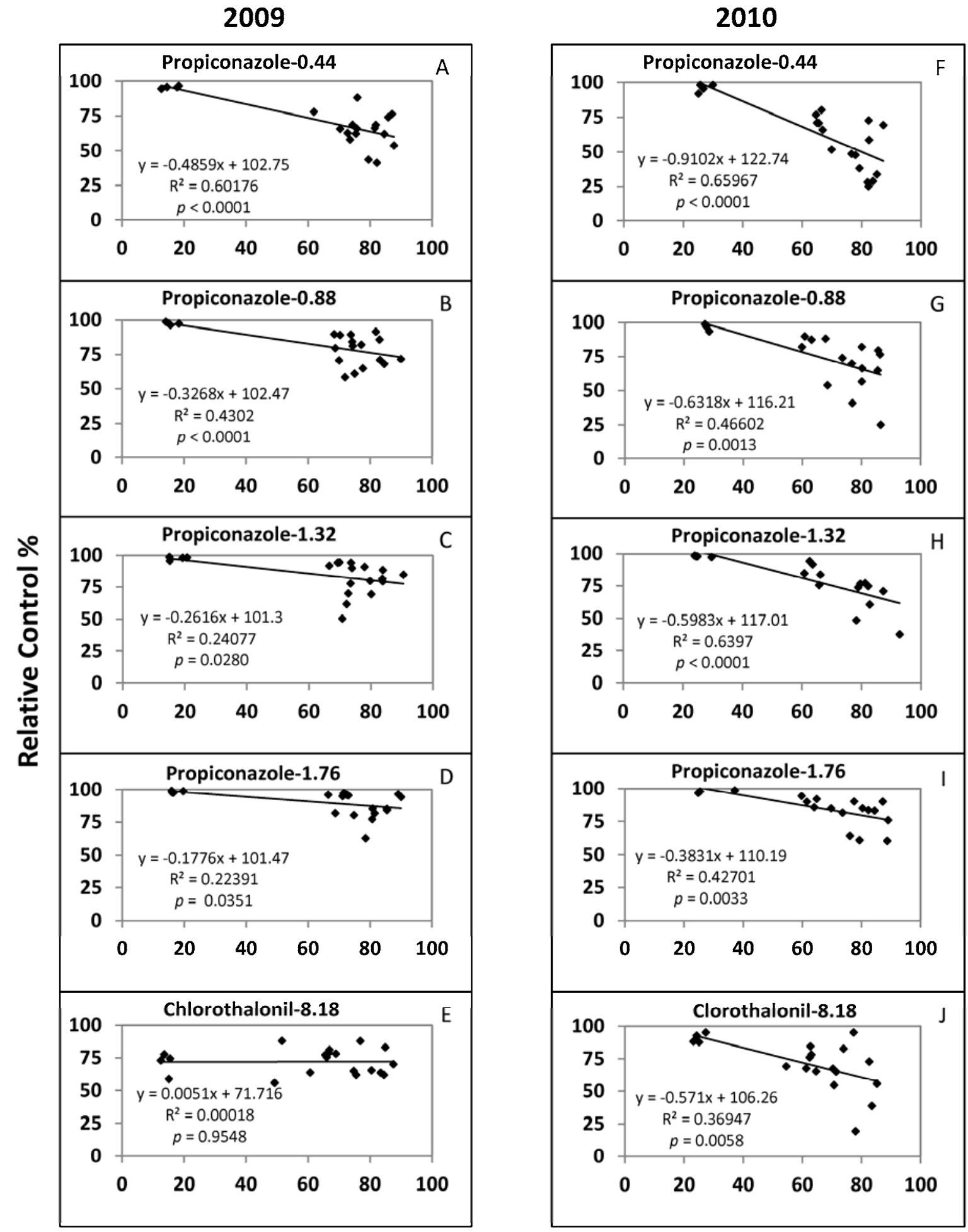

\section{Relative Mycelium Growth \%}

Fig. 4. Relationship between mean relative mycelium growth percentage (RMG\%) on the discriminatory concentration of propiconazole at $0.1 \mu \mathrm{g}$ a.i. $\mathrm{ml}^{-1}$ and mean relative control $(\mathrm{RC} \%)$ for propiconazole at $0.44,0.88,1.32$, and $1.76 \mathrm{~kg}_{\text {a.i. }} \mathrm{ha}^{-1}$ and chlorothalonil at $8.18 \mathrm{~kg}$ a.i. ha ${ }^{-1}$ at one baseline and four demethylation inhibitor (DMI)exposed populations on the final sample dates of 2009 and 2010. 
ported. This is the first report of bimodal population distributions existing in field conditions, despite numerous previous reports of DMI-insensitive fungal populations exhibiting unimodal population distributions formed under directional selection in various pathogen systems $(12,16,25)$. Interestingly, the development of the bimodal population distributions appears to have occurred in a differing fashion for HGC and HRCC. The bimodal population distribution likely developed at HRCC due to the absence of DMI fungicide use in the past years. However, approximately 20 years of DMI fungicide use (two to three applications per year) preceded the discontinued use of DMI fungicides at HRCC prior to this experiment. In contrast, past fungicide application records at $\mathrm{HGC}$ indicated moderate DMI usage (approximately two to three applications per year), with the exception of the year that preceded the 2009 field trial (seven DMI applications). Both locations were exposed to different selection pressures preceding field trials in 2009; however, both S. homoeocarpa populations were nearly identical in DMI sensitivity distribution.

On the other hand, WBGC is a 7-year-old golf course that has been under constant selection pressure since establishment (five DMI applications per year; Table 1). The S. homoeocarpa population distribution at WBGC was unimodal and highly homogenous throughout all sample collections. SMCC also displayed a unimodal population distribution, which was exposed to relatively low selection pressure (one to two DMI applications per year) prior to field efficacy testing (Table 1). Lower DMI selection pressure prior to field efficacy testing may have contributed to slightly lower mean RMG values at SMCC during the 2009 7-DAT, 2010 initial, and 2010 7-DAT sample times (Table 3). JTRF was not exposed to DMI fungicides prior to field efficacy testing and represented a baseline population in terms of in vitro sensitivity and field efficacy.

The unique population distributions at $\mathrm{HGC}$ and $\mathrm{HRCC}$ provided an interesting case study to examine RMG values for detection of practical DMI field resistance. HGC and HRCC displayed bimodal population distributions, with RMG ranges of 10 to $40 \%$ and 50 to $100 \%$ during the 2009 initial sample. Propiconazole application $\left(0.44 \mathrm{~kg}\right.$ a.i. $\left.\mathrm{ha}^{-1}\right)$ selected isolates with $>50 \%$ RMG in propiconazole-treated plots at each location for the 7-DAT and final sample times (Figs. 2A-C and 3A-C). This observation was again made in 2010; however, selection pressure applied by multiple propiconazole applications in 2009 might have had an effect on 2010 initial population distributions from all propiconazole treatments (Figs. 2D-F and 3D-F). Results indicate that propiconazoleinsensitive $S$. homoeocarpa isolates can be quickly selected by curative propiconazole applications if isolates with $>50 \%$ RMG exist. Furthermore, results also suggest that multiple propiconazole applications will cause the population shift to persist into the following season. In contrast, population shifts within untreated and chlorothalonil-treated plots yielded mixed results at both locations. A complete population shift in propiconazole sensitivity was observed at HGC among all treatments in the 2009 final sample (Fig. 2C). We speculate that selection of propiconazole-insensitive isolates in neighboring propiconazole-treated plots likely led to the population shift among untreated and chlorothalonil-treated plots in 2009 after the 7-DAT sample time at HGC. This trend was also observed at HRCC; however the frequency of propiconazoleinsensitive isolates sampled from untreated and chlorothaloniltreated plots was lower than HGC (Fig. 3C). Lack of buffer strips at HGC due to plot size restrictions may have played a role in the movement of propiconazole-insensitive isolates at HGC.

Ingress of propiconazole-insensitive $S$. homoeocarpa isolates suggests that isolates are capable of moving short distances and agrees with the previous work regarding the spatial dispersal radius range of S. homoeocarpa (19). Despite an overall increase in the frequency of propiconazole-insensitive isolates among all treatments in 2009 at HRCC, the frequency of propiconazole-insensitive isolates in the untreated and chlorothalonil-treated plots from the 2010 initial sample was similar to the 2009 initial sample (Fig. $3 \mathrm{~A}$ and D). This suggests that the 2009 final sample time popula- tion distribution may have been an artifact of the intense selection pressure surrounding non-propiconazole-treated plots at HRCC. This phenomenon was not replicated at HGC; however, the plant growth regulator (PGR) flurprimidol was applied $\left(0.28 \mathrm{~kg}\right.$ a.i. $\left.\mathrm{ha}^{-1}\right)$ on the experimental plot approximately 1 month prior to the initial sample at HGC in 2010 (personal communication with superintendent). Flurprimidol has been reported to have a fungistatic effect on $S$. homoeocarpa and $\mathrm{Ok}$ et al. (33) determined that flurprimidol $50 \%$ effective concentration $\left(\mathrm{EC}_{50}\right)$ values were highly correlated to $\mathrm{EC}_{50}$ values of DMI fungicides and suggested that flurprimidol may contribute to the selection of DMI-insensitive $S$. homoeocarpa isolates (6). It is possible the flurprimidol application at HGC influenced population distribution and convoluted further analysis of year-to-year variation at HGC. Further research examining the effect of PGRs on selection of DMI-insensitive isolates in field is warranted in S. homoeocarpa.

Field efficacy results revealed a strong relationship between in vitro sensitivity and RC values (Fig. 4). The baseline population JTRF was adequately controlled by propiconazole during both years of field efficacy testing and was significantly more sensitive in vitro than the four locations with prior DMI exposure. Although HGC, HRCC, SMCC, and WBGC all displayed mean RMG values $>50 \%$, our results revealed that the level of efficacy reduction varied among locations. Some variation can be attributed to lack of favorable environmental conditions that existed in the 2010 season. For instance, hot and dry conditions reduce guttation fluids (dew formation) in turfgrass and, in turn, reduce leaf moisture. Leaf moisture created by guttation fluids has been found to play a significant role in the infection process because the sugars and amino acids contained in guttation fluid (dew) provide a nutrition source for $S$. homoeocarpa prior to infection (40). Taking into account environmental variation, $\mathrm{RC}$ values did show that reduced propiconazole efficacy among HGC, HRCC, SMCC, and WBGC was least severe at SMCC in both years (Table 2). The SMCC RMG values from propiconazole treatments were lower in all sample times except for the 2009 initial (Table 3).

Recent findings in a wide array of fungi (Blumeriella jaapii, Botrytis cinerea, Monilinia fructicola, Penicillium digitatum, and Pyrenophora tritici-repentis) suggest that increased CYP51 gene expression (the specific gene DMI active ingredients target) or increased expression of efflux genes are responsible for decreased sensitivity to DMI fungicides $(17,18,26,34,36)$. Higher RC\% was observed as propiconazole rate increased at HGC, HRCC, SMCC, and WBGC in both years of field efficacy testing. This dose-response relationship suggests that DMI sensitivity is a quantitative phenotypic trait that is more likely to be influenced by gene expression or the interaction of multiple genes. If complete propiconazole failure occurred, this would have suggested that DMI sensitivity is controlled by a single major gene and would be more likely to be caused by a mutation to the target site of the active ingredient. Further examination for CYP51 and efflux gene expression is needed to clearly define the mechanisms that govern DMI insensitivity in $S$. homoeocarpa.

The results from this study have effectively determined the range of in vitro sensitivity values of $S$. homoeocarpa populations that cause practical field resistance to propiconazole. Results revealed that $S$. homoeocarpa populations exhibiting RMG values $>50 \%$ on the propiconazole discriminatory concentration $0.1 \mu \mathrm{g}$ a.i. $\mathrm{ml}^{-1}$ were capable of causing practical field resistance to propiconazole. Future studies should focus on developing management strategies for golf superintendents to manage populations of $S$. homoeocarpa that are found to exhibit practical field resistance to DMI fungicides and determination of the molecular mechanisms responsible for practical field resistance to DMI fungicides.

\section{Acknowledgments}

We thank the New England Regional Turfgrass Foundation, Golf Course Superintendents Association of Cape Cod, and Syngenta Crop Protection for funding this research; golf superintendents J. Burke, S. Curry, T. Griffin, M. Mansur, and R. Ruszala for allowing their golf courses to be used in this study; and J. Ban, J. Hulvey, M. Inoue, S. Lama, M. McGrath, and W. Autio for careful re- 
view of this manuscript, isolate collection, preparation of media, and culture work.

\section{Literature Cited}

1. Bennett, F. T. 1937. Dollar spot disease of turf and its casual organism Sclerotinia homoeocarpa N. SP. Ann. App. Biol. 24:236-257.

2. Bishop, P., Sorochan, J., Ownley, B. H., Samples, T. J., Windham, A. S., Windham, M. T., and Trigiano, R. N. 2008. Resistance of Sclerotinia homoeocarpa to iprodione, propiconazole, and thiophanate-methyl in Tennessee and northern Mississippi. Crop Sci. 48:1615-1620.

3. Brent, K. J., and Hollomon, D. W. 2007. Fungicide resistance in crop pathogens: how can it be managed? 2nd ed. FRAC Monograph No. 1. CropLife International, Brussels. http://www.frac.info.

4. Brownback, L. E., and Latin, R. 2002. Survey of isolates of Sclerotinia homoeocarpa in Indiana for sensitivity to three fungicides. (Abstr.) Phytopathology 92:S10.

5. Burpee, L. L. 1997. Control of dollar spot of creeping bentgrass caused by an isolate of Sclerotinia homoeocarpa resistant to benzimidazole and demethylation-inhibitor fungicides. Plant Dis. 81:1259-1263.

6. Burpee, L. L., Green, D. E., and Stephens, S. L. 1996. Interactive effects of plant growth regulators and fungicides on epidemics of dollar spot in creeping bentgrass. Plant Dis. 80:1245-1250.

7. Campbell, C. L., and Madden, L. V. 1990. Introduction to Plant Disease Epidemiology. John Wiley \& Sons, New York.

8. Cole, H., Taylor, B., and Duich, J. 1968. Evidence of differing tolerances to fungicides among isolates of Sclerotinia homoeocarpa. Phytopathology 58:683-686.

9. Couch, H. B. 1995. Diseases of Turfgrasses, 3rd ed. Krieger Publishing Company, Malabar, FL.

10. Detweiler, A. R., Vargas, J. M., and Danneberger, T. K. 1983. Resistance of Sclerotinia homoeocarpa to iprodione and benomyl. Plant Dis. 67:627-630.

11. De Waard. M. A., Georgopoulos, S. G., Hollomon, D. W., Ishii, H., Leroux, P., Ragsdale, N. N., and Schwinn, F. J. 1993. Chemical control of plant diseases: problems and prospects. Annu. Rev. Phytopathol. 31:403-421.

12. Eckert, J. W. 1988. Historical development of fungicide resistance in plant pathogens. Pages 1-3 in: Fungicide Resistance in North America. C. J. Delp, ed. American Phytopathological Society, St. Paul, MN.

13. Erickson, E. O., and Wilcox, W. F. 1997. Distributions of sensitivities to three sterol demethylation inhibitor fungicides among populations of $\mathrm{Un}$ cinula necator sensitive and resistant to triadimefon. Phytopathology 87:784-791.

14. Georgopoulos, S. G. 1988. Genetics and population dynamics. Pages 12-13. in: Fungicide Resistance in North America. C. J. Delp, ed. American Phytopathological Society, St. Paul, MN.

15. Gilstrap, D. M., Vargas, J. M., Golembiewski, R. C. Jones, A. L., and Schabenberger, O. 1997. Fungicide efficacy on demethylation inhibition (DMI) resistant Sclerotinia homoeocarpa. Int. Turfgrass Soc. Res. J. 8:875-881.

16. Golembiewski, R. C., Vargas, J. M., Jones, A. L., and Detweiler, A. R. 1995. Detection of demethylation inhibitor (DMI) resistance in Sclerotinia homoeocarpa populations. Plant Dis. 79:491-493.

17. Hamamoto, H., Hasegawa, K., Nakaune, R., Lee, Y. J., Makizumi, Y., Akutsu, K., and Hibi, T. 2000. Tandem repeat of a transcriptional enhancer upstream of the sterol 14a-demethylase gene (CYP51) in Penicillium digitatum. Appl. Environ. Microbiol. 66:3421-3426.

18. Hayashi, K., Schoonbeek, H., and De Waard, M. A. 2002. Expression of the ABC transporter BcatrD from Botrytis cinerea reduces sensitivity to sterol demethylation inhibitor fungicides. Pestic. Biochem. Physiol. 73:110-121.

19. Horvath, B. J., Kravchenko, A. N., Robertson, G. P., and Vargas, J. M. 2007. Geostatistical analysis of dollar spot epidemics occurring on a mixed sward of creeping bentgrass and annual bluegrass. Crop Sci. 47:1206-1216.

20. Hsiang, T., Liao, A., and Benedetto, D. 2007. Sensitivity of Sclerotinia homoeocarpa to demethylation-inhibiting fungicides in Ontario, Canada, after a decade of use. Plant Pathol. 56:500-507.

21. Jo, Y.-K., Niver, A. L. Rimelspach, J. W., and Boehm, M. J. 2006. Fungicide sensitivity of Sclerotinia homoeocarpa from golf courses in Ohio. Plant Dis. 90:807-813.

22. Koch, P. L., Grau, C. R., Jo, Y.-K., and Jung, G. 2009. Thiophanate-methyl and propiconazole sensitivity in Sclerotinia homoeocarpa populations from golf courses in Wisconsin and Massachusetts. Plant Dis. 93:100-105.

23. Köller, W. 1988. Sterol demethylation inhibitors: Mechanisms of action and resistance. Pages 79-88 in: Fungicide Resistance in North America. C. J. Delp, ed. American Phytopathological Society, St. Paul, MN.

24. Köller, W., and Scheinpflug, H. 1987. Fungal resistance to sterol biosynthesis inhibitors: A new challenge. Plant Dis. 71:1066-1074.

25. Köller, W., Wilcox, W. F., Barnard, J., Jones, A. L., and Braun, P. G. 1997. Detection and quantification of resistance of Venturia inaequalis populations to sterol demethylation inhibitors. Phytopathology 87:184-190.

26. Luo, C-X., and Schnabel, G. 2008. The cytochrome P450 lanosterol $14 \alpha-$ demethylase gene is a demethylation inhibitor fungicide resistance determinant in Monilinia fructicola field isolates from Georgia. Appl. Environ. Microbiol. 74:359-366.

27. Ma, B., and Tredway, L. 2010. Demethylation inhibitor (DMI) fungicide resistance mechanism in Sclerotinia homoeocarpa causing dollar spot in turfgrasses. (Abstr.) Phytopathology 100:S75.

28. Ma, Z., and Michailides, T. J. 2005. Advances in understanding molecular mechanisms of fungicide resistance and molecular detection of resistant genotypes in phytopathogenic fungi. Crop Prot. 24:853-863.

29. Ma, Z., Proffer, T. J., Jacobs, J. L., and Sundin, G. W. 2006. Overexpression of the $14 \alpha$-demethylase target gene (CYP51) mediates fungicide resistance in Blumeriella jaapii. Appl. Environ. Microbiol. 72:2581-2585.

30. McGrath, M. T. 2001. Fungicide resistance in cucurbit powdery mildew: experiences and challenges. Plant Dis. 85:236-245.

31. McGrath, M. T., and Shishkoff, N. 2001. Resistance to triadimefon and benomyl: Dynamics and impact on managing cucurbit Powdery mildew. Plant Dis. 85:147-154.

32. Miller, G. L., Stevenson, K. L., and Burpee, L. L. 2002. Sensitivity of Sclerotinia homoeocarpa isolates to propiconazole and impact on control of dollar spot. Plant Dis. 86:1240-1246.

33. Ok, C.-H., Popko, J., Campbell-Nelson, K., and Jung, G. 2011. In vitro assessment of Sclerotinia homoeocarpa resistance to fungicides and plant growth regulators. Plant Dis. 95:51-56.

34. Proffer, T. J., Berardi, R., Ma, Z., Nugent, J. E., Ehret, G. R., McManus, P. S., Jones, A. L., and Sudin, G. W. 2006. Occurrence, distribution, and polymerase chain reaction-based detection of resistance to sterol demethylation inhibitor fungicides in populations of Blumeriella jaapii in Michigan. Phytopathology 96:709-717.

35. Putman, A. I., Jung, G., and Kaminski, J. E. 2010. Geographic distribution of fungicide-insensitive Sclerotinia homoeocarpa isolates in the northeastern United States. Plant Dis. 94:186-195.

36. Reimann, S., and Deising, H. B. 2005. Inhibition of efflux transporter-mediated fungicide resistance in Pyrenophora tritici-repentis by a derivative of 4'-hydroxyflavone and enhancement of fungicide activity. Appl. Environ. Microbiol. 71:3269-3275.

37. Smiley, R. W., Dernoeden, P. H., and Clarke, B. B. 2005. Compendium of Turfgrass Diseases, 3rd ed. American Phytopathological Society, St. Paul, $\mathrm{MN}$

38. Tredway, L. 2005. Sensitivity to benzimidazole, dicarboxamide, and DMI fungicides in North Carolina populations of Sclerotinia homoeocarpa. (Abstr.) Phytopathology 95:S104.

39. Walsh, B., Ikeda, S. S., and Boland, G. J. 1999. Biology and management of dollar spot (Sclerotinia homoeocarpa); an important disease of turfgrass. HortScience 34:13-21.

40. Williams, D. W., Powell, A. J., Vincelli, P., and Dougherty, C. T. 1996. Dollar spot on bentgrass influenced by displacement of leaf surface moisture, nitrogen, and clipping removal. Crop Sci. 36:1304-1309.

41. Wong, F. P., and Wilcox, W. F. 2002. Sensitivity to azoxystrobin among isolates of Uncinula necator: Baseline distribution and relationship to myclobutanil sensitivity. Plant Dis. 86:394-404. 